\title{
Short- and mid-term outcome of transcatheter aortic valve implantation in patients with advanced age
}

\author{
Anna Olasinska-Wisniewska ${ }^{1}$, Marek Grygier ${ }^{1}$, Maciej Lesiak ${ }^{1}$, Olga Trojnarska ${ }^{1}$, \\ Aleksander Araszkiewicz ${ }^{1}$, Anna Komosa ${ }^{1}$, Marcin Misterski ${ }^{2}$, Marek Jemielity ${ }^{2}$, \\ Marek Proch ${ }^{3}$, Stefan Grajek ${ }^{1}$
}

${ }^{1} 1^{\text {st }}$ Department of Cardiology, University of Medical Sciences, Poznan, Poland

${ }^{2}$ Department of Cardiac Surgery and Transplantology, University of Medical Sciences, Poznan, Poland

${ }^{3}$ The Province Neuropsychiatric Hospital, Koscian, Poland

\begin{abstract}
Background: In patients treated with transcatheter aortic valve implantation (TAVI), age is recognized as one of the most important risk factors. The aim of our study was to evaluate whether early and midterm results of TAVI were worse in patients over 85 year old compared with the younger population.

Methods: From September 2010 to November 2015, 162 consecutive patients (mean age $78.4 \pm 7.1$ years, $47.5 \%$ females) underwent TAVI in our Institution. Patients were divided into two groups: 1) elderly ( $\geq 85$ year old) and 2) younger patients $(<85$ year old). Primary clinical study endpoints were the following: death, myocardial infarction, stroke, major and minor access site, and bleeding complications. The secondary endpoints included: pacemaker implantation rate, paravalvular leakage, acute kidney injury, and duration of hospitalization.

Results: Twenty-six patients were 85 or older (mean $87.5 \pm 2.1$ ). In the remaining 136 (84\%), the average age was $76.7 \pm 6.4$. Baseline clinical profiles were similar in both groups, though history of previous cardiac surgery $(p=0.0047)$ and chronic obstructive pulmonary disease $(p=0.0099)$ were more common in the younger group, and glomerular filtration rate was lower in the older group $(p=0.045)$. Major, life threatening and minor bleeding complications, as well as vascular access site complications did not differ between the two groups. Rates of myocardial infarction and stroke were comparably low in both groups. Similar results were also found in the incidence of secondary endpoints. In-hospital mortality and 1-year mortality did not differ between groups.

Conclusions: TAVI in patients aged 85 and older is still a relatively safe procedure and age itself should not be a discriminatory factor in TAVI qualification. (Cardiol J 2017; 24, 4: 358-363)
\end{abstract}

Key words: aortic stenosis, age, transcatheter aortic valve implantation (TAVI)

\section{Introduction}

Transcatheter aortic valve implantation (TAVI) has currently become an established method of treatment of patients with severe aortic stenosis who are inoperable or with very high surgical risk. Among risk factors, age is one of the most important taken into account in patients' risk assessment, including EuroScore and Society of Thoracic Surgeons (STS) score.

There are still doubts whether age itself is the strongest predictor of survival in TAVI patients.

Therefore, we have decided to compare periand post-procedural outcomes in patients who were 85 years old or older to the younger ones.

Address for correspondence: Anna Olasinska-Wisniewska, MD, PhD, $1^{\text {st }}$ Department of Cardiology, Poznan University of Medical Sciences, ul. Długa 1/2, 61-848 Poznań, Poland, tel: + 48 603862713; e-mail: anna.olasinska@poczta.onet.pl 


\section{Methods}

From September 2010 to November 2015, 162 consecutive patients (mean age $78.4 \pm 7.1$ years, 47.5\% females) underwent TAVI in our Institution with the implantation of CoreValve $(n=109)$, CoreValve Evolut $(\mathrm{n}=27)$, Lotus $(\mathrm{n}=16)$ or Symetis $(\mathrm{n}=8)$. Patients were divided into two groups: 1) elderly ( $\geq 85$ year old) and 2 ) younger patients ( $<85$ year old). The demographic, clinical, and peri-procedural data were analyzed.

The diagnosis of severe aortic stenosis was made on routine clinical and echocardiographic criteria. Patients were eligible for TAVI on the basis of the institutional heart team's decision (general cardiologist, interventional cardiologist, echocardiographer and cardiac surgeon). The pre-procedural evaluation included coronary angiography, transthoracic echocardiography (TTE) and transesophageal echocardiography (TEE), contrast-enhanced computed tomography with offline reconstructions to evaluate the aorta, femoral and iliac arteries.

All procedures were performed by the same team of cardiologists, cardiac surgeons, and anesthesiologists in a hybrid operating room.

The procedures were performed under general anesthesia $(\mathrm{n}=142,87.7 \%)$ or deep sedation $(\mathrm{n}=20,12.3 \%)$. TEE monitoring was used based on the operator's decision (56\% of cases). In each patient, a temporary pacemaker was inserted from jugular or femoral vein for rapid pacing and as a prevention of potential consequences of atrioventricular block.

In patients with percutaneous femoral approach, Prostar $^{\mathrm{TM}}$ system or two Proglides ${ }^{\mathrm{TM}}$ were introduced before insertion of vascular sheath. Aortic valve predilatation was performed in 108 patients with an undersized Z-MED II- ${ }^{\circledR}$ balloon (NuMED Inc., USA). Once the prosthesis was correctly positioned, expanded, and deployed, contrast injection was performed to assess the presence and degree of paravalvular leak (PVL). Control angiography of the access site was performed to assess vessel patency and possible bleeding. For transapical access, left anterolateral minithoracotomy was performed in the $5^{\text {th }}$ or $6^{\text {th }}$ intercostal space. Pericardiotomy was performed and two 3-0 Prolene purse string sutures reinforced with Teflon pledgets were placed at the apex. The apex was punctured and soft guide wire was introduced across stenotic valve under fluoroscopic control. Then a $14 \mathrm{~F}$ sheath was introduced into the left ventricular apex to maintain intraventricular access. Balloon valvuloplasty was performed during rapid ventricular pacing. The prosthesis was delivered through the introducer sheath, positioned across the aortic annulus, and deployed. The delivery system was removed and the apical purse-string sutures were tied. An $18 \mathrm{~F}$ chest tube was inserted to drain the left pleural cavity and the routine chest wall closure was performed.

After the procedure, patients were monitored for heart rhythm and basic life parameters. One day after an uncomplicated procedure, rehabilitation was started.

Antiplatelet therapy consisted of aspirin $75 \mathrm{mg}$ daily life-long, and in patients with a recent history of coronary angioplasty or acute coronary syndrome, clopidogrel $75 \mathrm{mg}$ per day was added, according to current guidelines [1]. In patients with atrial fibrillation, oral anticoagulants (OACs and NOACs) were stopped before the procedure and resumed on the second day after procedure.

Primary clinical study endpoints were the following: death, myocardial infarction (MI), stroke, major and minor access site, and bleeding complications. The secondary endpoints included: the incidence of pacemaker implantation, PVL, acute kidney injury (AKI), and duration of hospitalization defined in concordance with the Valve Academic Research Consortium-2 (VARC-2) definitions [2]. The study was approved by our institutional committee and respected the principles outlined in the Declaration of Helsinki.

\section{Follow-up}

All patients underwent follow-up visits including overall medical evaluation, TTE, lab tests and electrocardiogram at 1 -month, 6 -months, 1 year, and then annually. In rare cases, where hospital visits were not possible, telephone contact was obtained.

\section{Statistical analysis}

Continuous variables were reported as mean and standard deviation and compared using the unpaired t test or nonparametric Mann-Whitney test. Categorical variables were reported as counts or percentages and compared by the Fisher's exact test. All tests were 2 -sided. $P$ values less than 0.05 were considered statistically significant. Statistical analysis was performed using GraphPad InStat 3 (GraphPad Software, Inc. USA).

\section{Results}

Twenty-six (16\%) patients were 85 or older (mean $87.5 \pm 2.1$, range $85-92$ years). In the 
Table 1. Demography and clinical characteristics of the study group.

\begin{tabular}{|c|c|c|c|}
\hline & $\begin{array}{l}\text { Group } 1-\text { younger } \\
\text { (age }<85 ; n=136 \text { ) }\end{array}$ & $\begin{array}{l}\text { Group } 2-\text { older } \\
(\text { age } \geq 85 ; n=26)\end{array}$ & $\mathbf{P}$ \\
\hline Age [years] & $76.7 \pm 6.4$ & $87.5 \pm 2.1$ & \\
\hline Logistic EuroScore [\%] & $19.5 \pm 15.2$ & $18.5 \pm 7.6$ & NS \\
\hline EuroScore II [\%] & $7.4 \pm 7.6$ & $5.7 \pm 3.1$ & NS \\
\hline STS score $[\%]$ & $13.8 \pm 11.8$ & $14.4 \pm 9.7$ & NS \\
\hline Female & $63(46.3 \%)$ & $14(53.8 \%)$ & NS \\
\hline Hypertension & $91(66.9 \%)$ & $15(57.7 \%)$ & NS \\
\hline Diabetes & $46(33.8 \%)$ & $9(34.6 \%)$ & NS \\
\hline Body mass index $\left[\mathrm{kg} / \mathrm{m}^{2}\right]$ & $27.6 \pm 4.3$ & $27.7 \pm 4.5$ & NS \\
\hline Coronary artery disease & $80(58.8 \%)$ & $14(53.8 \%)$ & NS \\
\hline History of myocardial infarction & $45(33.1 \%)$ & $9(34.6 \%)$ & NS \\
\hline Atrial fibrillation & $46(33.8 \%)$ & $8(30.8 \%)$ & NS \\
\hline History of coronary artery bypass grafting & $30(22 \%)$ & $0(90 \%)$ & 0.0047 \\
\hline History of any previous cardiac surgery & $34(25.7 \%)$ & $0(0 \%)$ & 0.0026 \\
\hline History of percutaneous coronary intervention & $49(36 \%)$ & $10(38.5 \%)$ & NS \\
\hline History of aortic balloon valvuloplasty & $7(5.1 \%)$ & $0(0 \%)$ & NS \\
\hline Chronic obstructive pulmonary disease or asthma & $37(27.2 \%)$ & $1(3.9 \%)$ & 0.0099 \\
\hline Peripheral arterial disease & $32(23.5 \%)$ & $3(11.5 \%)$ & NS \\
\hline Carotid artery disease & $42(30.9 \%)$ & $9(34.6 \%)$ & NS \\
\hline Stroke or transient ischemic attack & $14(10.3 \%)$ & $3(11.5 \%)$ & NS \\
\hline Frailty (Katz ADL index less than 5 ) & $36(26.5 \%)$ & $14(53.8 \%)$ & 0.01 \\
\hline Glomerular filtration rate $[\mathrm{mL} / \mathrm{min}]$ & $57.8 \pm 19.3$ & $49 \pm 15.3$ & 0.045 \\
\hline Creatinine level at baseline $[\mu \mathrm{mol} / \mathrm{L}]$ & $113.6 \pm 38$ & $122.6 \pm 42$ & NS \\
\hline NT-proBNP level at baseline $[\mathrm{pg} / \mathrm{mL}]$ & $4722.1 \pm 5492.5$ & $6080.6 \pm 6624.9$ & NS \\
\hline Left ventricular ejection fraction at baseline [\%] & $51.3 \pm 11.4$ & $53 \pm 9.3$ & NS \\
\hline Peak aortic gradient at baseline $[\mathrm{mm} \mathrm{Hg}]$ & $91.8 \pm 27.6$ & $93.4 \pm 18.8$ & NS \\
\hline Mean aortic gradient at baseline $[\mathrm{mm} \mathrm{Hg}]$ & $56.6 \pm 18$ & $56.8 \pm 12.4$ & NS \\
\hline
\end{tabular}

ADL - Activities of Daily Living; NT-proBNP — N-terminal pro-B-type natriuretic peptide; STS — Society of Thoracic Surgeons

remaining $136(84 \%)$ patients, the average age was $76.7 \pm 6.4$ (range $57-84$ years). Baseline characteristics of both groups are presented in Table 1 . The estimated mean risk scores for the entire population were as follows: logistic EuroScore $19.3 \pm 14.2 \%$, EuroScore II $7.11 \pm 7.1 \%$, and STS mortality risk score $13.9 \pm 11.5$. Both groups did not differ in terms of peri-operative risk scores, including logistic EuroScore $(\mathrm{p}=0.3)$, EuroScore II $(\mathrm{p}=0.9)$, and STS mortality risk $(\mathrm{p}=0.4)$. Women comprised $53.9 \%$ of the elderly group and $46.3 \%$ of the younger group $(p=0.5)$. Baseline clinical profiles were quite similar, though history of previous cardiac surgery, including coronary artery bypass grafting $(\mathrm{p}=0.0047)$ and chronic obstructive pulmonary disease (COPD) $(p=0.0099)$, were more common in younger group, whereas glomerular filtration rate was lower in the older group $(\mathrm{p}=0.045)$. Pre-procedural echocardiographic findings were similar in both groups. Patients with transapical procedures did not present significantly higher risk scores than the rest of the study group: logistic EuroScore $(16.7 \pm 9$ vs. $19.5 \pm 14.5, \mathrm{p}=0.9)$, EuroScore II ( $8.7 \pm 7.5$ vs. $7 \pm 7.1, \mathrm{p}=0.2)$, and STS score (22.9 \pm 25.1 vs. $13.4 \pm 10.3, \mathrm{p}=0.9)$.

Prosthesis implantation was successful in $99.3 \%$ of the younger group $(\mathrm{n}=135)$ and in $96.2 \%$ of the older patients $(n=25), p=0.3$. Two patients died during the procedure ( 1 from the younger and 1 from the older group). All patients in the older group had femoral access, while in the younger group $121(89 \%)$ had femoral, 6 (4.4\%) directaorta, 8 (5.9\%) transapical route, and 1 patient had carotid access. 
Table 2. Procedural and post-procedural results.

\begin{tabular}{|c|c|c|c|}
\hline & $\begin{array}{l}\text { Group } 1-\text { younger } \\
\text { (age }<85 ; n=136 \text { ) }\end{array}$ & $\begin{array}{c}\text { Group } 2 \text { - older } \\
(\text { age } \geq 85 ; n=26)\end{array}$ & $\mathbf{P}$ \\
\hline \multicolumn{4}{|l|}{ Approach: } \\
\hline Femoral & $121(89 \%)$ & $26(100 \%)$ & \\
\hline Direct aorta & $6(4.4 \%)$ & $0(0 \%)$ & \\
\hline Transapical & $8(5.9 \%)$ & $0(0 \%)$ & \\
\hline Carotid & $1(0.7 \%)$ & $0(0 \%)$ & \\
\hline CoreValve & $93(68.4 \%)$ & $16(61.5 \%)$ & \\
\hline CoreValve Evolut $\mathrm{R}$ & $23(16.9 \%)$ & $4(15.4 \%)$ & \\
\hline Symetis & $8(5.9 \%)$ & $0(0 \%)$ & \\
\hline Lotus & $11(8.1 \%)$ & $5(19.2 \%)$ & \\
\hline General anesthesia & $122(89.7 \%)$ & $20(76.9 \%)$ & 0.098 \\
\hline Pacemaker implantation & $26(19.1 \%)$ & $4(15.4 \%)$ & NS \\
\hline Myocardial infarction & $1(0.7 \%)$ & $0(0 \%)$ & NS \\
\hline Stroke & $1(0.7 \%)$ & $1(3.9 \%)$ & NS \\
\hline Paravalvular leakage mild & $57(41.9 \%)$ & $7(26.9 \%)$ & NS \\
\hline Paravalvular leakage moderate & $13(9.6 \%)$ & $5(19.2 \%)$ & NS \\
\hline Acute kidney injury & $52(38.2 \%)$ & $11(42.3 \%)$ & NS \\
\hline Creatinine post-procedural max level $[\mu \mathrm{mol} / \mathrm{L}]$ & $163.6 \pm 100.6$ & $167.7 \pm 79.7$ & NS \\
\hline Bleeding minor & $14(10.3 \%)$ & $2(7.7 \%)$ & NS \\
\hline Bleeding major & $11(8.1 \%)$ & $0(0 \%)$ & NS \\
\hline Bleeding life threatening & $10(7.4 \%)$ & $1(3.9 \%)$ & NS \\
\hline Vascular complications minor & $13(9.6 \%)$ & $1(3.9 \%)$ & NS \\
\hline Vascular complications major & $10(7.4 \%)$ & $1(3.9 \%)$ & NS \\
\hline Hospitalization [days] & $9.8 \pm 8.6$ & $8.8 \pm 5$ & NS \\
\hline
\end{tabular}

In-hospital mortality did not differ significantly between the groups. Rates of MI and stroke were also comparably low in both groups (Table 2 ).

Major, life threatening and minor bleeding complications, as well as vascular access site complications did not differ between the two groups. Similar results were also found in both groups (Table 2$)$ regarding the incidence of PVL $(\mathrm{p}=0.2)$, pacemaker implantation $(\mathrm{p}=0.8)$ and the length of hospitalization (older group $8.8 \pm 5$ days and younger group $9.8 \pm 8.6$ days, $\mathrm{p}=0.4$ ).

One-month follow-up was available for all patients, 1-year - for a total of 135 (83\%) patients who completed 12-month follow-up. Five patients died during 30 days after the procedure in the younger group and two in the older group $(\mathrm{p}=0.6)$. One-year mortality was $15.4 \%$ in the younger and $7.7 \%$ in the older group $(\mathrm{p}=0.4)$. Results are presented in Table 3 and Figure 1. In the younger group, there were 4 in-hospital deaths directly related to procedural complications, and 1 death in the course of decompensated heart failure. More-
Table 3. All-cause mortality at follow-up.

\begin{tabular}{lccc}
\hline & $\begin{array}{c}\text { Group 1 } \\
\text { - younger } \\
\text { (age < 85) }\end{array}$ & $\begin{array}{c}\text { Group 2 } \\
\text { - older } \\
\text { (age } \geq 85)\end{array}$ & P \\
\hline In-hospital death & $5(3.7 \%)$ & $2(7.7 \%)$ & 0.3 \\
1-month mortality & $6(4.4 \%)$ & $2(7.7 \%)$ & 0.6 \\
1-year mortality & $21(15.4 \%)$ & $2(7.7 \%)$ & 0.4 \\
\hline
\end{tabular}

over, during 1-year observation, 4 cardiac deaths and 9 non-cardiac deaths were noted, whereas the reason of 3 additional deaths is unknown. In the older group, there were 2 in-hospital deaths related to procedure complications.

After exclusion of 15 patients with access site other than femoral, the minor $(\mathrm{p}=1)$, major $(\mathrm{p}=0.35)$, life threatening $(p=1)$ bleeding complications, minor $(\mathrm{p}=0.46)$ and major $(\mathrm{p}=0.7)$ vascular complications, as well as in-hospital $(\mathrm{p}=0.3)$ and 1-year $(\mathrm{p}=0.5)$ death rate were still not significant. 


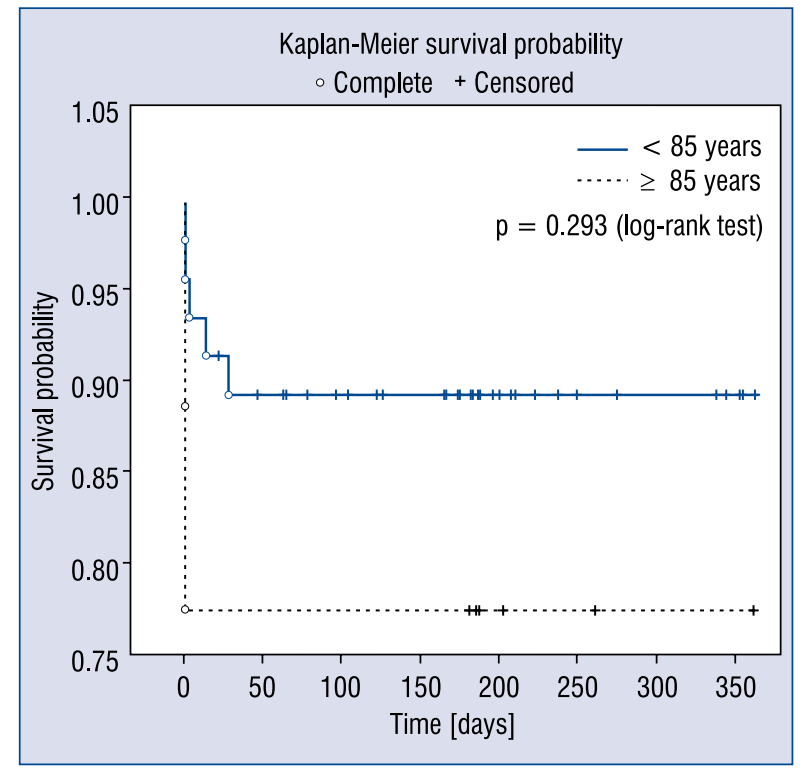

Figure 1. Kaplan-Meier 12-month survival curves of the study group.

\section{Discussion}

Our results suggest that TAVI can be a safe procedure even in very elderly patients. Those who were 85 or older, compared with the younger group, had similar rate of death, MI, stroke, major and minor access site, or bleeding complications, as well as the rate of pacemaker implantation, PVL, AKI and duration of hospitalization.

Until recently, elderly patients were often disqualified from surgical aortic valve replacement as the risk of the procedure seemed to exceed expected benefits [3]. The age was believed to be an independent risk factor of periprocedural mortality and morbidity. Therefore, age has been included in every risk score, including EuroScore and STS score. For example, the EuroScore II predicts higher mortality rate in an 85-year-old male without co-morbidities undergoing aortic valve replacement (1.36\%) than in a 60-year-old male with chronic kidney disease and severe lung disease with long-term use of bronchodilators (1.1\%). Patients who are currently qualified for surgical aortic valve replacement may have numerous co-morbidities included in risk scores, as well as some additional, e.g. fragility, history of cancer, osteoporosis, porcelain aorta, mediastinal radiation, glucosteroid therapy, and others. Therefore, risk assessment for aortic valve replacement or TAVI, especially in elderly patients, may be sometimes problematic.
Our study confirms that TAVI offers a safe treatment option even for elderly patients. It is an important finding, since currently majority of TAVI patients are aged, with approximately $16 \%$ of them being $\geq 90$ years of age in the United States clinical practice $[4,5]$. It is worth mentioning that TAVI registries and trials included patients with mean age of $80[6,7]$. The tendency is quite stable over time. The STS/ACC Transcatheter Valve Therapy (TVT) registry [8] underlined that TAVI candidates are still elderly with several co-morbidities. In their analysis of 26,414 procedures performed in two periods of time, (2012-2013 and 2014) the mean age of patients was 82 years between 2012 and 2013 and 81 years in 2014 . Moreover, $91 \%$ of patients were $\geq 70$ years of age, whereas $68 \%$ were $\geq 80$ years of age.

Studies [4, 9-11] which assessed feasibility and safety of TAVI in very old patients, including nonagenarians [9], underline good mid-term results of the procedure, improvement in physical and mental quality of life $[4,9,10]$, self-reported health [11], and in New York Heart Association functional capacity [9]. Elderly individuals experienced better in-hospital recovery and similar short- and mid-term mortality compared to those who underwent surgical aortic valve replacement [4]. Moreover, TAVI enables early rehabilitation and discharge $[12,13]$.

The mid-term results of elderly patients were good in our study. Abramowitz et al. [9] and Havakuk et al. [14] noted higher rate of minor vascular complications and Yamamoto et al. [15] higher rate of major vascular complication in elderly subjects. These observations might be attributed to the increased rate of transfemoral vs. alternative access sites and higher rate of calcification of femoral arteries in an advanced age. All elderly patients in our study had transfemoral access, but neither major nor minor vascular complication rates were higher when compared to the younger group. Similar to other reports [9], our younger group presented higher percentage of COPD and history of cardiac surgery, which may be explained as qualification of more severely ill patients to TAVI.

Alsara et al. [4] reported that 30-day and 1 -year mortality rates were statistically higher in older compared with younger patients undergoing TAVI, but we did not confirm this observation in our study.

\section{Limitations of the study}

The main limitations of our study are the heterogeneity and small number of patients in the 
study group. However, such analysis reflects typical, real world population of patients with severe aortic stenosis treated currently with TAVI in most of institutions.

\section{Conclusions}

Transcatheter aortic valve implantation in patients aged 85 or older is still a relatively safe procedure and age itself should not be a discriminatory factor in TAVI qualification.

\section{Conflict of interest: None declared}

\section{References}

1. Windecker S, Kolh P, Alfonso F, et al. Authors/Task Force members. 2014 ESC/EACTS Guidelines on myocardial revascularization: The Task Force on Myocardial Revascularization of the European Society of Cardiology (ESC) and the European Association for Cardio-Thoracic Surgery (EACTS)Developed with the special contribution of the European Association of Percutaneous Cardiovascular Interventions (EAPCI). Eur Heart J. 2014; 35(37): 2541-2619, doi: 10.1093/eurheartj/ehu278, indexed in Pubmed: 25173339.

2. Kappetein AP, Head SJ, Genereux P, et al. Updated standardized endpoint definitions for transcatheter aortic valve implantation: the Valve Academic Research Consortium-2 consensus document (VARC-2). Eur J Cardiothoracic Surg, 2012; 42(5): S45-S60, doi: 10.1093/ejcts/ezs533, indexed in Pubmed: 23022744.

3. Iung B, Cachier A, Baron G, et al. Decision-making in elderly patients with severe aortic stenosis: why are so many denied surgery? Eur Heart J. 2005; 26(24): 2714-2720, doi: 10.1093/ eurheartj/ehi471, indexed in Pubmed: 16141261.

4. Alsara O, Alsarah A, Laird-Fick H. Advanced age and the clinical outcomes of transcatheter aortic valve implantation. J Geriatr Cardiol. 2014; 11(2): 163-170, doi: 10.3969/j.issn.16715411.2014.02.004, indexed in Pubmed: 25009568.

5. Thyregod HG, Holmberg F, Gerds TA, et al. Heart Team therapeutic decision-making and treatment in severe aortic valve stenosis. Scand Cardiovasc J. 2016; 50(3): 146-153, doi: 10.3109 /14017431.2016.1148825, indexed in Pubmed: 26825285.

6. Eggebrecht H, Mehta RH. Transcatheter aortic valve implantation (TAVI) in Germany 2008-2014: on its way to standard ther- apy for aortic valve stenosis in the elderly? EuroIntervention. 2016; 11(9): 1029-1033, doi: 10.4244/EIJY15M09_11, indexed in Pubmed: 26384006.

7. Leon MB, Smith CR, Mack M, et al. PARTNER Trial Investigators. Transcatheter aortic-valve implantation for aortic stenosis in patients who cannot undergo surgery. N Engl J Med. 2010; 363(17): 1597-1607, doi: 10.1056/NEJMoa1008232, indexed in Pubmed: 20961243.

8. Holmes DR, Nishimura RA, Grover FL, et al. STS/ACC TVT Registry. Annual Outcomes With Transcatheter Valve Therapy: From the STS/ACC TVT Registry. J Am Coll Cardiol. 2015; 66(25): 2813-2823, doi: 10.1016/j.jacc.2015.10.021, indexed in Pubmed: 26652232.

9. Abramowitz Y, Chakravarty T, Jilaihawi H, et al. Comparison of Outcomes of Transcatheter Aortic Valve Implantation in Patients $\geq 90$ Years Versus < 90 Years. Am J Cardiol. 2015; 116(7): 1110-1115, doi: 10.1016/j.amjcard.2015.06.033, indexed in Pubmed: 26235927.

10. Bekeredjian R, Krumsdorf U, Chorianopoulos E, et al. Usefulness of percutaneous aortic valve implantation to improve quality of life in patients $>80$ years of age. Am J Cardiol. 2010; 106(12): 1777-1781, doi: 10.1016/j.amjcard.2010.08.017, indexed in Pubmed: 21055715 .

11. Olsen S, Fridlund B, Eide L, et al. Changes in self-reported health and quality of life in octogenarian patients one month after transcatheter aortic valve implantation. Eur J Cardiovasc Nurs. 2017; 16(1): 79-87, doi: 10.1177/1474515116641297, indexed in Pubmed: 27036955.

12. Barbanti M, Capranzano P, Ohno Y, et al. Early discharge after transfemoral transcatheter aortic valve implantation. Heart. 2015; 101(18): 1485-1490, doi: 10.1136/heartjnl-2014-307351, indexed in Pubmed: 26076940.

13. Durand E, Eltchaninoff $\mathrm{H}$, Canville A, et al. Feasibility and safety of early discharge after transfemoral transcatheter aortic valve implantation with the Edwards SAPIEN-XT prosthesis. Am J Cardiol. 2015; 115(8): 1116-1122, doi: 10.1016/j.amjcard.2015.01.546, indexed in Pubmed: 25726383.

14. Havakuk O, Finkelstein A, Steinvil A, et al. Comparison of outcomes in patients $\leq 85$ versus $>85$ years of age undergoing transcatheter aortic-valve implantation. Am J Cardiol. 2014; 113(1): 138-141, doi: 10.1016/j.amjcard.2013.09.044, indexed in Pubmed: 24210675.

15. Yamamoto M, Meguro K, Mouillet G, et al. Comparison of effectiveness and safety of transcatheter aortic valve implantation in patients aged $\geq 90$ years versus $<90$ years. Am J Cardiol. 2012; 110(8): 1156-1163, doi: 10.1016/j.amjcard.2012.05.058, indexed in Pubmed: 23021601. 